\title{
Rechargeable membraneless glucose biobattery: Towards solid-state cathodes for implantable enzymatic devices
}

\author{
Alireza Ahmadian Yazdi a , Roberto Preite ${ }^{\text {a }}$, Ross D. Milton ${ }^{\text {b }}$, David P. Hickey ${ }^{\text {, }}$ \\ Shelley D. Minteer ${ }^{b}$ and Jie Xu ${ }^{\text {a, } 1}$ \\ a Department of Mechanical and Industrial Engineering, University of Illinois at Chicago, Chicago, IL 60607, USA \\ b Departments of Chemistry and Materials Science and Engineering, University of Utah, Salt Lake City, UT 84112, USA
}

\begin{abstract}
Enzymatic biobatteries can be implanted in living organisms to exploit the chemical energy stored in physiological fluids. Generally, commonly-used electron donors (such as sugars) are ubiquitous in physiological environments, while electron acceptors such as oxygen are limited due to many factors including solubility, temperature, and pressure. The wide range of solid-state cathodes, however, may replace the need for oxygen breathing electrodes and serve in enzymatic biobatteries for implantable devices. Here, we have fabricated a glucose biobattery suitable for in vivo applications employing a glucose oxidase (GOx) anode coupled to a solid-state Prussian Blue (PB) thin-film cathode. PB is a non-toxic material and its electrochemistry enables fast regeneration if used in a secondary cell. This novel biobattery can effectively operate in a membraneless architecture as PB can reduce the peroxide produced by some oxidase enzymes. The resulting biobattery delivers a maximum power and current density of $44 \mu \mathrm{W} \mathrm{cm}{ }^{-2}$ and $0.9 \mathrm{~mA} \mathrm{~cm}^{-2}$, respectively, which is $c a$. $37 \%$ and $180 \%$ higher than an equivalent enzymatic fuel cell equipped with a bilirubin oxidase cathode. Moreover, the biobattery demonstrated a stable performance over 20 cycles of charging and discharging periods with only $c a .3 \%$ loss of operating voltage.
\end{abstract}

Keywords: Enzymatic fuel cell, Glucose Biobattery, Implantable devices, Solid-state cathode, Prussian Blue

\section{Introduction}

Biofuel cells offer unique features in comparison to chemical fuel cells, such as the ability to operate at room temperature and near neutral $\mathrm{pH}$, biocompatibility, ease of miniaturization, possessing a small environmental footprint and low-cost power production [1-3]. A biofuel cell consists of an anode and a cathode that are separated by a liquid electrolyte, often employing a membrane to regulate the transport of ions between the cathodic and anodic compartments. At the anode a biofuel (electron donor) is oxidized with the aid of biological catalysts such as enzymes or whole microbes. Electrons that are released via the oxidation of biomass pass through an external load to produce power and eventually combine at the cathode with protons to reduce an

\footnotetext{
${ }^{1}$ Corresponding author:

E-mail address: jiexu@uic.edu (J. Xu)
} 
electron acceptor, such as oxygen. Typically, metal catalysts (such as platinum) or biomolecules (such as enzymes) are used to catalyze the cathodic reaction. Enzymatic fuel cells (EFCs) are devices that convert biofuels such as glucose $[4,5]$, fructose $[6,7]$, or alcohols [8], to electricity utilizing enzymatic catalysts at the anode and/or cathode. A wide range of redox enzymes have been used in EFCs providing options for many energy-related applications, such as low-power electronics [9], lab-on-a-chip devices [10], self-powered sensors [11], and implantable energy harvesting units [12].

Although there are various limitations to the use of EFCs for in vivo power generation, these limitations are expected to be overcome in the near future due to a growing interest in utilizing EFCs for implantable biomedical devices. One reason is that most of the biocatalysts utilized in EFCs are evolved to efficiently catalyze the reactions at physiological temperature and $\mathrm{pH}$, yielding products that are tolerable to the complex host environment [12]. Due to the availability of biofuels (i.e., glucose) in many living species and physiological fluids, glucose EFCs are promising units to harvest energy within living organisms for implantable devices. However, there are a number of hurdles that limit the applicability of the conventional design of EFCs in an in vivo environment. First of all, molecular oxygen $\left(\mathrm{O}_{2}\right)$ is the primary choice of electron acceptor due to its high standard reduction potential ( 1.229 V vs. standard hydrogen electrode) in traditional designs. However, physiological $\mathrm{O}_{2}$ concentrations are often low and constantly fluctuating $(\sim 0.1 \mathrm{mM})[12,13]$, leading to variations in performance and low current densities for EFCs. The use of air-breathing cathodes could be considered as a solution for such limitations, although they should be assembled in subcutaneous devices (limiting the range of applications) and may impose extra challenges in their design. Secondly, most EFC cathodes utilizing $\mathrm{O}_{2}$-reducing enzymes are single-use, where enzymatic activity diminishes over time.

Prussian Blue $(\mathrm{PB})$ or ferric ferrocyanide $\left(\mathrm{Fe}_{4}^{\mathrm{IIII}}\left[\mathrm{Fe}_{2}^{\mathrm{II}}(\mathrm{CN})_{6}\right]_{3}\right)$ belongs to a family of materials known as transition metal hexacyanides with a general chemical formula of $\mathrm{A}_{\mathrm{x}} \mathrm{PR}(\mathrm{CN})_{6}$ where $\mathrm{A}$ is an alkali cation and $\mathrm{P}$ and $\mathrm{R}$ are iron (Fe) atoms for the most common type of PB [14]. The cubic face-centered structure of the PB crystal with wide channels allows for the rapid intercalation of metal ions and protons (Fig. 1). Therefore, PB and its analogous have been extensively explored as cathodic materials for monovalent [15-18] and multivalent [6, 19-22] metal-ion batteries. Moreover, PB has long served as a reliable catalyst for biosensor applications [23-25]. For example, Sekretaryova et al. [25] introduced a self-powered cholesterol biosensor that utilized PB alongside immobilized cholesterol oxidase (ChOx), whereby $\mathrm{H}_{2} \mathrm{O}_{2}$ (produced in proportion to cholesterol oxidation) is detected by PB. More recently, PB has been tested in biofuel cells and biobatteries. Yu et al. [26] introduced a novel integrated photoelectrochemical biofuel cell (PBFC) by taking advantage of the PB/Prussian White (PW) redox couple for storage and conversion of solar energy and biomass into electricity. Addo et al. [27] reported the transition of an ethanol biofuel cell towards a rechargeable biobattery, utilizing NADdependent alcohol dehydrogenase $(\mathrm{ADH})$ as the anodic catalyst immersed in butyl-3-methylimidazolium chloride (BMIMCl) ionic liquid, and a PB paste as the cathodic material. The resulting dual-chamber alcohol biobattery oxidizes ethanol to acetaldehyde during the discharge phase, followed by the conversion of acetaldehyde to ethanol in the charging period. Simultaneously, Berlin green (BG) is reduced to PB during discharge at the cathode and oxidized back to PB when the battery is charged. Xie et al. [14] reported the use of PB as the cathode material of a single-chamber membraneless microbial biobattery. In this biobattery the 
reduction of the PB film is driven by the oxidation of glucose catalyzed by the bacterial biofilm at the anode. Their biobattery reached net biomass energy recovery efficiencies of 18-33\%.

Here, we propose the use of solid-state PB as the cathode material in enzymatic implantable devices. On this basis, a rechargeable glucose biobattery was fabricated with an aqueous electrolyte based on a PB thin-film cathode and glucose oxidase (GOx) enzymatic anode, both of which were immobilized on carbon paper substrates. To the best of our knowledge, this is the first study showing the use of solid-state PB thin-films in a rechargeable glucose enzymatic biobattery. The resulting membraneless biobattery offers several advantages for powering both implantable devices and portable sensors: (i) PB is a non-toxic and low-cost material with a simple and scalable synthesis from earth abundant elements, (ii) the use of a solid-state cathode eliminates the need for $\mathrm{O}_{2}$ as the electron acceptor and is not associated with the energy loss due to the diffusion overpotential of dissolved $\mathrm{O}_{2}$, (iii) hydrogen peroxide $\left(\mathrm{H}_{2} \mathrm{O}_{2}\right)$ produced by undesirable side reactions at oxidase-based bioanodes can be reduced by the PB cathode, where Milton et al. [28, 29] previously demonstrated that the parasitic production of $\mathrm{H}_{2} \mathrm{O}_{2}$ at the oxidase bioanodes by immobilized GOx negatively influence the performance of both laccase and bilirubin oxidase (BOx) biocathodes and the final power output of singlechamber EFCs, (iv) PB-based cathodes can be regenerated after reduction by being exposed to ambient air, and this process does not require the input of energy, and (v) the proposed fabrication technique of the PB thin-film modified with multi-walled carbon nanotubes (MWCNTs) can be implemented for producing ultra-thin power units such as paper-based green batteries.
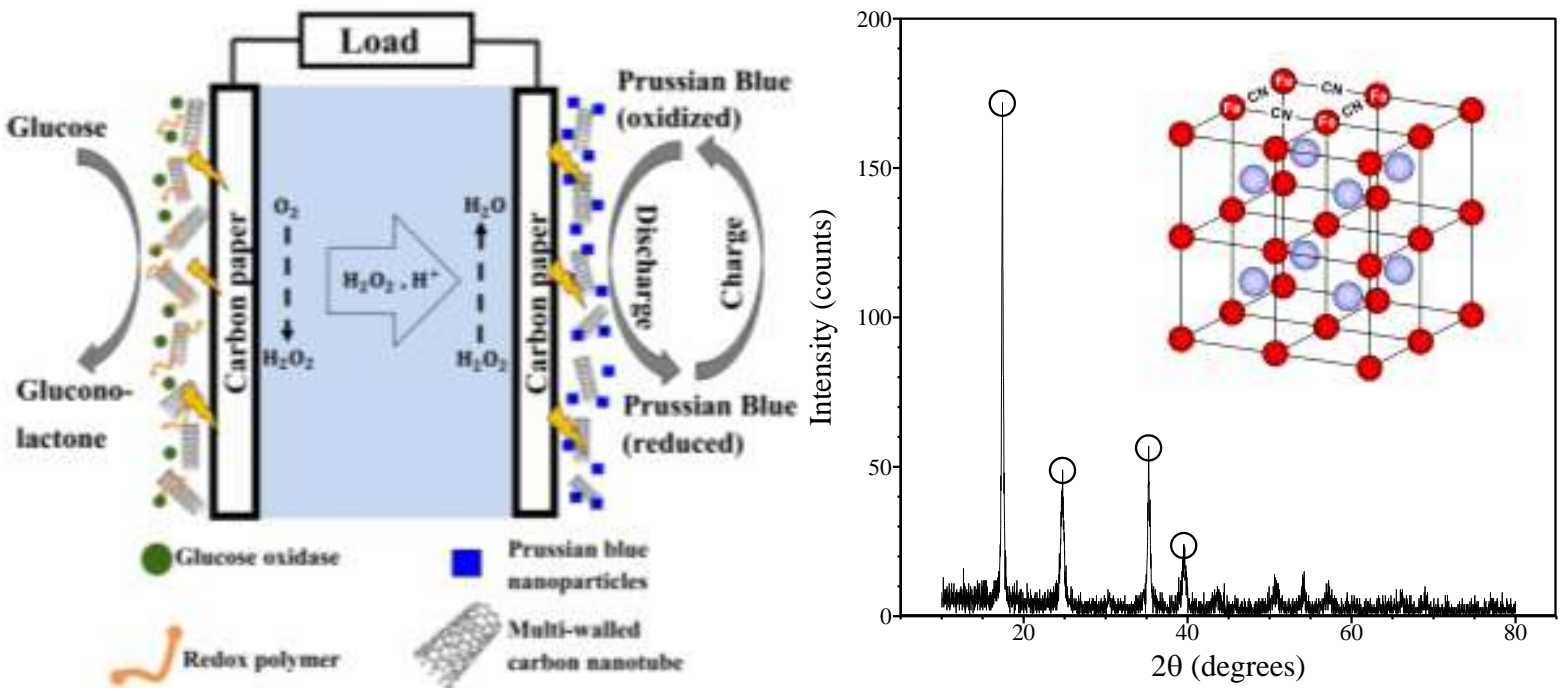

Fig. 1. (Left) Schematic of the glucose biobattery configuration. (Right) Powder X-ray diffraction (XRD) patterns of the as-prepared PB nanoparticles, with the crystal structure of PB being shown on the top right of the graph.

\section{Experimental}

\subsection{Materials and chemicals}

Glucose oxidase (GOx, from 'Aspergillus niger', EC 1.1.3.4, Type X-S), tetrabutylammonium bromide (TBAB), (6-Bromohexyl) ferrocene, and Nafion $5 \mathrm{wt} \%$ suspension were purchased from Sigma-Aldrich. Bilirubin oxidase (BOx from 'Myrothecium sp.', EC 1.3.3.5) was ordered from Amano enzyme (Japan). LPEI 
(MW 100,000) and ethylene glycol diglycidyl ether (EGDGE) were purchased from Polyscience Inc., Warrington, PA.

$\mathrm{HCl}(30 \%)$ was purchased from Macron Fine Chemicals ${ }^{\mathrm{TM}}$. Ferric chloride $\mathrm{FeCl}_{3}$, and potassium ferricyanide $\mathrm{K}_{3}\left[\mathrm{Fe}(\mathrm{CN})_{6}\right]$ were obtained from Sigma-Aldrich. Hydrogen peroxide (30\%), citric acid, sodium phosphate dibasic anhydrous, and dextrose (D-glucose) anhydrous were purchased from Fisher Scientific. Toray carbon paper 0.90" (non-wet proofed) was purchased from Fuel Cell Earth. Carboxyl-modified multi-walled carbon nanotubes (MWCNT) were obtained from www.cheaptubes.com. All chemicals were used as received without further purification.

Hexylferrocenyl-LPEI (Fc-C 6 -LPEI) was synthesized following procedures reported in [30, 31]. Briefly, $10 \mathrm{~mL}$ of acetonitrile was mixed with $300 \mathrm{mg}$ of linear polyethylenimine. The solution was then refluxed under vigorous agitation for approximately 10 minutes. Afterwards, $2 \mathrm{~mL}$ of ethanol and $380 \mathrm{mg}$ of (6Bromohexyl)ferrocene were added to the mixture and refluxed overnight. Finally, the polymer extracted by removing the solvents from the mixture with the aid of diethyl ether. Synthesis of TBAB modified Nafion was adopted from [32, 33]. Anthracene-modified multi-walled carbon nanotubes (An-MWCNTs) were modified as described in [34-36].

Prussian Blue nanoparticles were synthesized by a chemical precipitation method, adopted from [14, 37]. Briefly, $0.5 \mathrm{M} \mathrm{K}_{3}\left[\mathrm{Fe}(\mathrm{CN})_{6}\right]$ and $0.5 \mathrm{M} \mathrm{FeCl}_{3}$ were added under vigorous agitation to water that had been adjusted to $\mathrm{pH} 2.0$ using $\mathrm{HCl}$. Afterwards, the solution was stirred overnight at $50{ }^{\circ} \mathrm{C}$, allowing the evaporation of solvent. Finally, the precipitates were collected by centrifugation at $4000 \mathrm{rpm}$, and washed with excessive deionized (DI) water. This process was repeated several times until a clear separation between the chemical precipitates and the solvent were observed. The nanoparticles were then dried for one hour at $100{ }^{\circ} \mathrm{C}$. The asprepared PB nanoparticles were evaluated with powder X-ray diffraction (XRD) to verify the formation of PB crystal. As shown by Fig. 1 (right), the pronounced peaks of the XRD graph at $2 \theta$ of 17.4, 25.6, 35.2, and 29.4 marked with circles are ascribed to the crystal structure of $\mathrm{Fe}\left[\mathrm{Fe}(\mathrm{CN})_{6}\right]_{3} \cdot \mathrm{xH}_{2} \mathrm{O}[37,38]$.

\subsection{Instrumentation}

Electrochemical analysis was conducted utilizing a CHI 660E potentiostat (CH Instrument, USA). Electrode characterization and half-cell tests were conducted in a three-electrode setup where a saturated calomel electrode (SCE) and a platinum mesh $\left(1 \mathrm{~cm}^{2}\right.$ projected surface area) were used as reference and counter electrodes, respectively. All the electrochemical tests were performed at room temperature $\left(21^{\circ} \mathrm{C}\right)$ and by using a $0.2 \mathrm{M}$ citrate/phosphate buffer solution $(\mathrm{pH} 7.0)$ as the supporting electrolyte. Current and power densities were normalized with respect to the projected surface area of the anode. Battery cells were fabricated using a desktop 3D-printer (Formlabs Form 2), with clear photopolymer resin.

\subsection{Bioelectrode preparation}

The GOx and BOx electrodes were prepared following the steps described in $[28,39]$. Briefly, for $3 \mathrm{~cm}^{2} \mathrm{coating}$ of GOx anodes, $140 \mu \mathrm{L}$ of $10 \mathrm{mg} \mathrm{mL}^{-1}$ hexylferrocenyl-LPEI polymer in DI water was mixed with $60 \mu \mathrm{L}$ of 10 
$\mathrm{mg} \mathrm{mL}^{-1}$ GOx solution in DI water. Then, $5.5 \mu \mathrm{L}$ of EGDGE solution (10\% v/v in DI water) was added to the mixture, followed by vortex mixing until homogenization. The solution was then spread on carbon paper electrodes, and left at room temperature to dry for 24 hours. To coat $3 \mathrm{~cm}^{2}$ of BOx cathodes, $1.5 \mathrm{mg}$ of BOx was dissolved in $75 \mu \mathrm{L}$ of $0.2 \mathrm{M}$ citrate/phosphate buffer ( $\mathrm{pH}$ 7.0). Then, 7.5 mg of An-MWCNTs were added to the solution, followed by consecutive steps of vortex mixing (1 min) and sonication (15 second), until the solution is homogenized. Afterwards, $25 \mu \mathrm{L}$ of TBAB-modified Nafion were added to the mixture, followed by three steps of vortex mixing and sonication. The resulting slurry was then brush-coated on one side of a carbon paper substrate, and left under the positive air flow to dry for at least 4 hours.

\subsection{PB electrode preparation}

To prepare $1 \mathrm{~cm}^{2}$ of PB electrode, $6 \mathrm{mg}$ of the PB nanoparticles were added to $100 \mu \mathrm{L}$ of isopropyl alcohol and $30 \mu \mathrm{L}$ of DI water with $14 \mathrm{M} \Omega \mathrm{cm}$ resistivity. The solution was vortex mixed thoroughly until a dark blue color was observed. Afterwards, $2 \mathrm{mg}$ of carboxylated MWCNT (referred to as MWCNT) were added to the mixture, followed by sonication for 30 minutes. Then, $5 \mu \mathrm{L}$ of $5 \mathrm{wt} \%$ Nafion was added to the mixture, vortex mixed for 30 seconds, and sonicated for another half an hour to make sure a stable dispersion of nanoparticles was achieved. The slurry was then brush-coated layer-by-layer on one side of the carbon paper. In this process, after brushing one layer, the electrode was immediately exposed for a few seconds to light illumination which helps to evaporate the solvent. The as-prepared electrodes were then placed in an oven overnight at $100{ }^{\circ} \mathrm{C}$ which was found to stabilize the PB/MWCNT composite. In this study, we refer to the PB/MWCNT composite electrodes as PB thin-film electrodes. Before performing the tests, the bare surface of the carbon paper was coated with wax to exclude it from the electrochemically active area of the cathode.

\section{Results and discussion}

In the first step, the immobilization of the enzymes on the carbon paper substrate was investigated via cyclic voltammetric $(\mathrm{CV})$ studies. For the GOx bioanode, it was determined that a minor modification of the untreated carbon paper with MWCNT enhances the conductive sites for electron transfer and slightly improves the onset potential for glucose oxidation (Fig. 2a). The open circuit voltage (OCV) test of the anodic half-cell in buffer containing $0.1 \mathrm{M}$ glucose demonstrates that the onset potential decreases from approximately $0.1 \mathrm{~V}$ to $-0.08 \mathrm{~V}$ (vs. SCE). This improvement enhances the OCV of the biobattery, and is mainly attributed to the increased active surface area for chemical adsorption and overcoming diffusion limitations. Moreover, the catalytic current is improved by $c a$. $24 \%$ due to the enhancement in the surface conductivity by MWCNT. Fig. 2b represents the $\mathrm{CVs}$ of the as-prepared $\mathrm{O}_{2}$-reducing $\mathrm{BOx}$ cathode. As seen, the injection of $\mathrm{O}_{2}$ introduces a significant catalytic current, showing the successful immobilization of BOx in an An-MWCNT/TBAB-modified Nafion on carbon paper. 

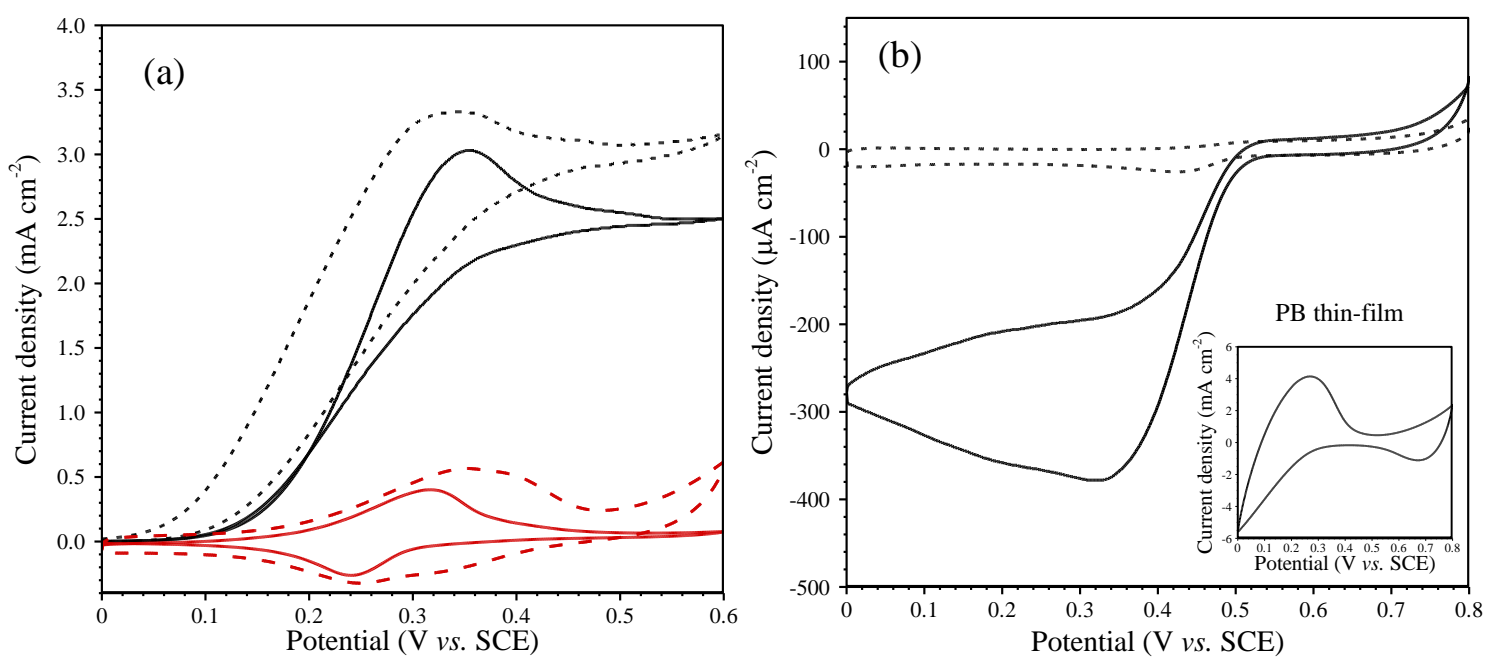

Fig. 2. Representative cyclic voltammograms of the as-prepared enzymatic electrodes at a scan rate of 1 $\mathrm{mV} \mathrm{s}^{-1}$. (a) GOx/Fc-C 6 -LPEI (__ ) and GOx/Fc-C 6 -LPEI /MWCNT anode (_ _ _ ) in the presence (black) and the absence (red) of $0.1 \mathrm{M}$ glucose. (b) BOx/An-MWCNT/TBAB-modified Nafion cathode in the presence (_ $)$ and absence (_ - - )of $\mathrm{O}_{2}$. (b, inset) PB-thin film in the absence of $\mathrm{O}_{2}$.

In the next step, the power output of the glucose biobattery with the setup shown in Fig. 1 was tested and evaluated against a conventional EFC in which the PB cathode was replaced by the BOx cathode $\left(\mathrm{O}_{2}\right.$-reducing) with the electrolyte being saturated by $\mathrm{O}_{2}$. The power curves are obtained by sweeping the voltage between the $\mathrm{OCV}$ of the cell to 0 at a scan rate of $1 \mathrm{mV} \mathrm{s}^{-1}$. Before the linear polarization tests, the OCV of the cell setup was measured for at least 500 seconds, until a stable curve is obtained. The OCV of the glucose|PB biobattery was $c a .0 .45 \mathrm{~V}$ while the $\mathrm{OCV}$ of the glucose $\mid O_{2} \mathrm{EFC}$ was $c a .0 .6 \mathrm{~V}$, which is ascribed to the larger theoretical half-cell potential of the $\mathrm{O}_{2}$-reducing cathode. As shown by Fig. 3a, the use of the solid-state PB thin-film cathode yielded an increased power output (by $c a .37 \%$ ) and short-circuit current density (by $c a .180 \%$ ) to 44 $\mu \mathrm{W} \mathrm{cm}{ }^{-2}$ and $0.9 \mathrm{~mA} \mathrm{~cm}^{-2}$, respectively, compared to an EFC equipped with an $\mathrm{O}_{2}$-reducing cathode. Factors contributing to this performance are mainly associated with the transition from the enzymatic reduction of $\mathrm{O}_{2}$ to the solid-state electrode in the cathode side as defined below.

First, the use of a solid-state electrode overcomes the diffusion overpotential (especially in hydrostatic/quiescent electrolytes). Secondly, achievable concentrations of dissolved $\mathrm{O}_{2}$ in the electrolyte is limited by temperature and pressure, requiring the input of energy. Third, the $\mathrm{O}_{2}$ dissolved in the bulk electrolyte (for the cathode) may in fact interfere in the oxidation of glucose at the anode (in membraneless configurations). For instance, it is well understood that $\mathrm{GOx}$ reduces $\mathrm{O}_{2}$ to $\mathrm{H}_{2} \mathrm{O}_{2}$ by the chemical reaction below, in which flavin adenine dinucleotide (FAD) is the redox co-factor of the GOx [28]:

$\mathrm{GOx}\left(\mathrm{FADH}_{2}\right)+\mathrm{O}_{2} \rightarrow \mathrm{GOx}(\mathrm{FAD})+\mathrm{H}_{2} \mathrm{O}_{2}$

The production of $\mathrm{H}_{2} \mathrm{O}_{2}$ may reduce enzymatic activity of both the cathode and anode, which is a key factor of reduced power output after long operational cycles [28]. Unfortunately, utilizing an $\mathrm{O}_{2}$-reducing cathode has 
been the primary choice for most implantable devices, since assembling an air-breathing gas diffusion layer for in vivo applications is problematic, especially for membraneless and miniaturized designs. On the other hand, the solid-state PB cathode eliminates the need for $\mathrm{O}_{2}$, and $\mathrm{H}_{2} \mathrm{O}_{2}$ produced by the GOx bioanode can be reduced to water in neutral media by the following reaction $[37,40]$ :

$\mathrm{H}_{2} \mathrm{O}_{2}+2 \mathrm{H}^{+}+2 \mathrm{e}^{-} \rightarrow 2 \mathrm{H}_{2} \mathrm{O}$

In order to see if the PB thin-film cathode can reduce small amounts of $\mathrm{H}_{2} \mathrm{O}_{2}$ in the bulk electrolyte during operation, the cathodic half-cell was evaluated by chronopotentiometry, in which a constant reducing current is applied to the PB electrode. As shown by Fig. 3b, a sudden increase in the cathodic half-cell potential is observed after the addition of $20 \mathrm{mM}$ of $\mathrm{H}_{2} \mathrm{O}_{2}$ at $\mathrm{t}=100 \mathrm{sec}$. This increase in the voltage shows the appropriate $\mathrm{H}_{2} \mathrm{O}_{2}$ sensitivity of the as-prepared PB thin-fim electrode, and is attributed to the reduction potential of $\mathrm{H}_{2} \mathrm{O}_{2}$ [1.77 vs. standard hydrogen electrode (SHE)].
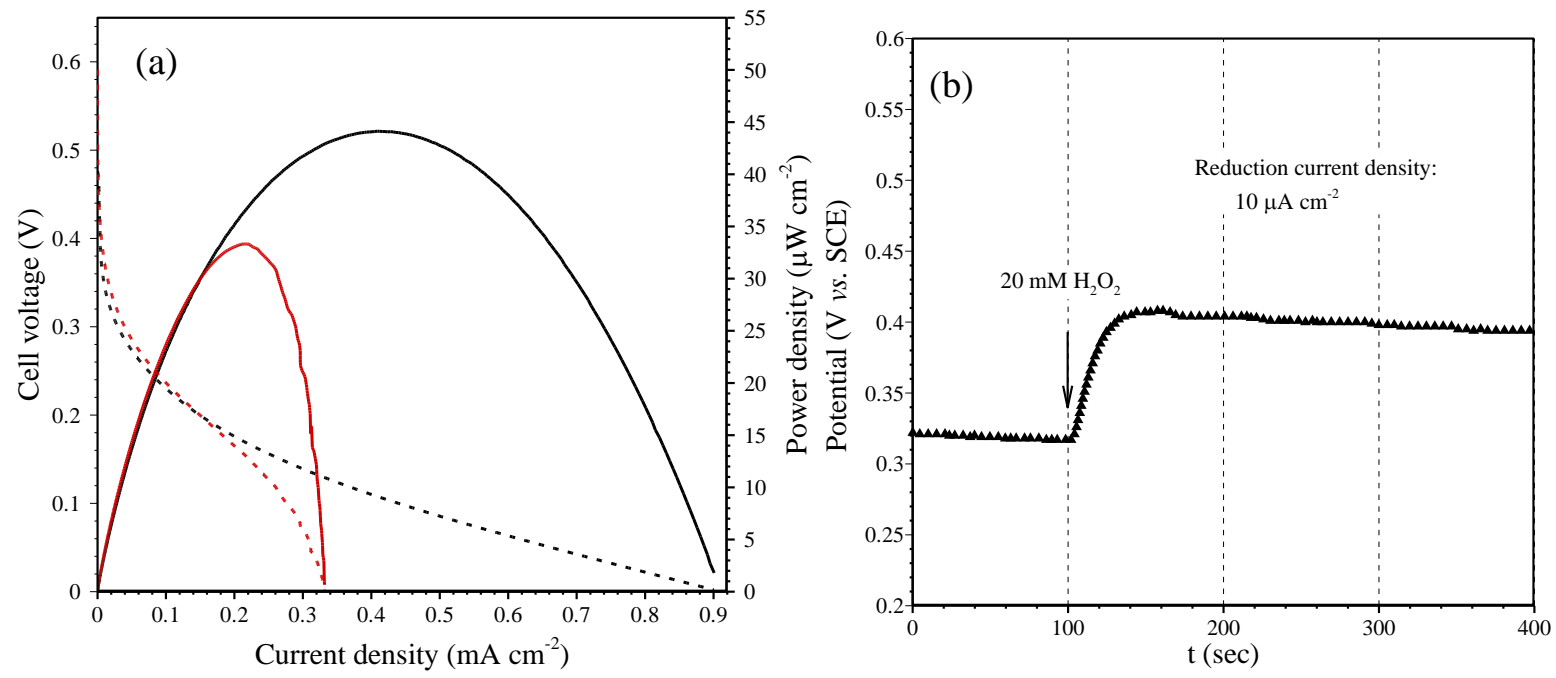

Fig. 3. (a) Power curves (solid lines) and linear polarization graphs (dashed lines) of the glucose|PB (black), and glucose $\mid \mathrm{O}_{2}$ (red) in the buffer solution containing $0.1 \mathrm{M}$ glucose for both cases, and saturated by $\mathrm{O}_{2}$ for the latter case. The linear polarization graphs were obtained by sweeping the voltage between the OCV of the cell to 0 at a scan rate of $1 \mathrm{mV} \mathrm{s}^{-1}$. The OCVs were measured by maintaining the cell at zero current until a stable voltage is observed. (b) Chronopotentiometry study of the PB thin-film cathode in the buffer solution being injected by

$$
\mathrm{H}_{2} \mathrm{O}_{2} \text { at } \mathrm{t}=100 \mathrm{~s} \text {. }
$$

Many studies have shown that the cyclic voltammetric behavior of PB involves two redox states namely Berlin Green (BG) (or Prussian Yellow in some cases) and Prussian White (PW). BG is the fully oxidized state of PB occurring at high potentials, while PW is the fully reduced and colorless state of PB at low potentials. Here we intend to show that the as-prepared PB thin-film electrodes may be regenerated by ambient air (charging phase) after being partially reduced to PW in the biobattery (discharging phase). Note that, unlike refs. [14, 27], we do not electrochemically reduce (before the discharging period) or oxidize (during charging period) the as-prepared PB thin-film electrodes, which is beneficial to maintain the energy balance. As a proof-of-concept, a battery cell 
was 3D-printed and filled with buffer solution containing $0.1 \mathrm{M}$ glucose, with the electrodes being located $2 \mathrm{~cm}$ apart. Note that since the electrolyte is not purged with $\mathrm{O}_{2}$, we expect $\mathrm{H}_{2} \mathrm{O}_{2}$ formation by the GOx bioanode remains at low concentrations, as demonstrated in Fig. 3b; thus, its reduction by the PB thin-film cathode is not the main source of overall power production. The cell is then maintained at a constant current density of 10 $\mu \mathrm{A} \mathrm{cm}{ }^{-2}$ for 20 cycles. In each cycle, after 5 minutes of discharge, the PB thin-film cathode was removed from the cell, exposed to ambient air for 5 minutes and installed back into the battery for another discharge period of the same time. Fig. 4a represents the cycling data of the glucose biobattery. First of all, in the very beginning of each discharge phase, the cell voltage drops by nearly $0.7 \mathrm{~V}$. However, this reduction is mainly attributed to the voltage loss in the anodic half-cell, as shown by the chronopotentiometry study of the GOx electrode in Fig. 4b. The average cell voltage during the discharge phase was then calculated and plotted versus the cycle number in Fig. 4 a. As seen, the average cell voltage drops by nearly $3 \%$ after 20 cycles which is mainly attributed to the loss of capacity of the PB, and deterioration of the thin-film due to continual removal, drying and reintroduction to the aqueous electrolyte. The latter was concluded due to the cracks that appeared in the PB thin-film after operation, as shown by comparing the SEM images in Fig. $4 \mathrm{c}$ and $\mathrm{d}$.
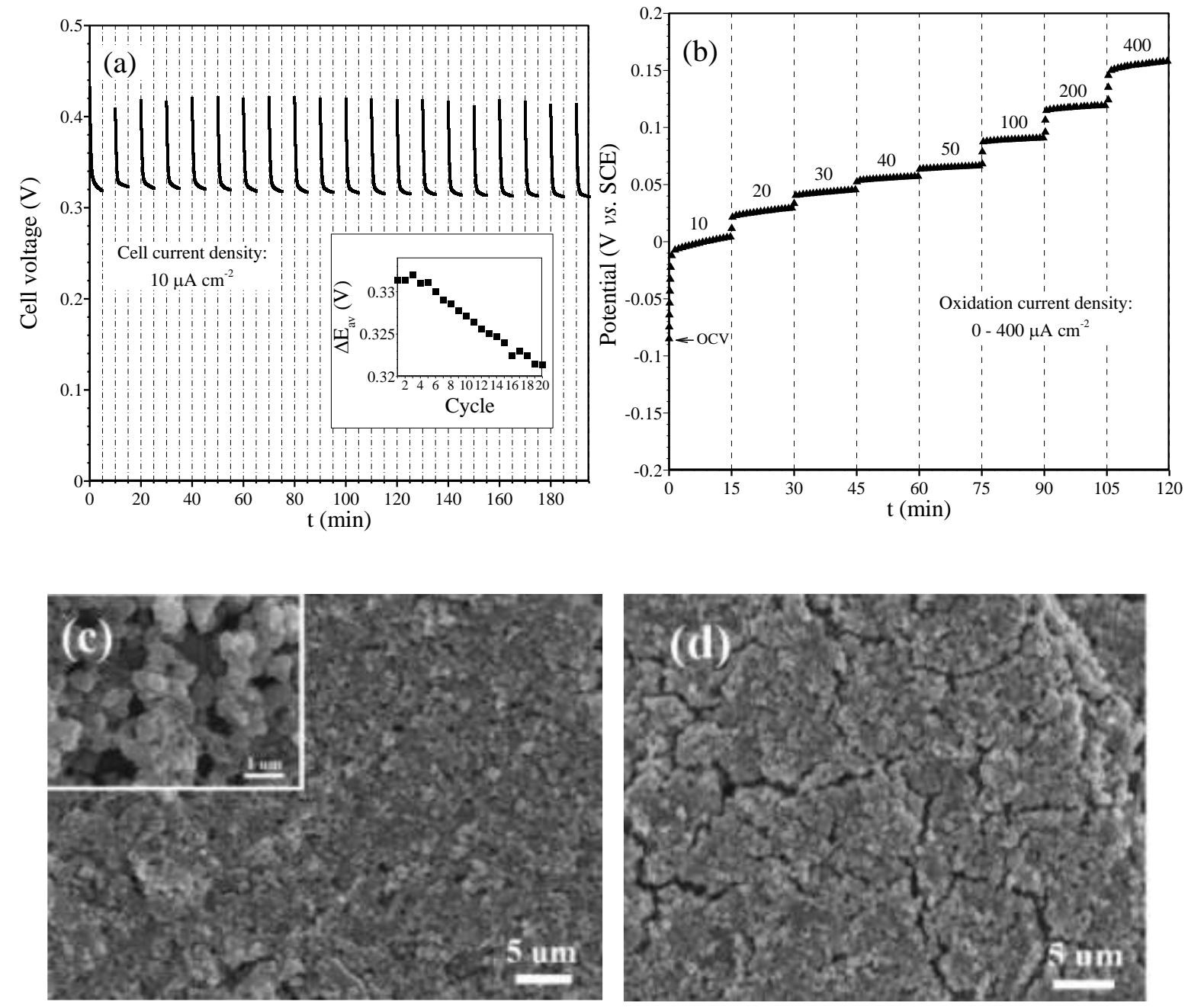
Fig. 4. (a) Cycling performance of the glucose biobattery, and the average cell voltage being plotted versus the cycle number. (b) Chronopotentiometry study of the anodic half-cell. Scanning electron microscopy (SEM) images of the PB thin-film on carbon paper substrate before (c) and after (d) the cycling study. All electrochemical tests were performed in buffer solution containing $0.1 \mathrm{M}$ glucose.

If the biobattery is to be recharged by dissolving $\mathrm{O}_{2}$ in the bulk electrolyte, the amount of $\mathrm{H}_{2} \mathrm{O}_{2}$ produced by the GOx bioanode can end up being higher than the dissolved $\mathrm{O}_{2}$ concentration. As long as the sensitivity of the PB thin-film cathode towards reducing $\mathrm{H}_{2} \mathrm{O}_{2}$ is retained, this is expected to benefit the biobattery during off cycles, as the reduction of $\mathrm{H}_{2} \mathrm{O}_{2}$ by the $\mathrm{PB}$ thin-film cathode can recover some energy losses. However, dissolving $\mathrm{O}_{2}$ requires the input of energy, and we insist on minimizing the overall energy input to exploit power from glucose. Therefore, unless techniques (such as designing a flow-through device) are devised to introduce $\mathrm{O}_{2}$ containing electrolyte to charge the biobattery without spending energy, the biobattery would mostly benefit from being recharged by ambient air.

With respect to in vivo application, we do not envisage utilizing the proposed biobattery in areas where oxygen availability is extremely low. Even if this is the case, the proposed biobattery will turn into a primary cell with the performance characteristics shown in Fig. 3a, which demonstrates noticeable improvement compared to the conventional EFCs and is potentially applicable for in vivo power generation. In the presence of ample oxygen concentrations required for running a conventional EFC, the use of the PB cathode is still preferable due its ability to reduce the $\mathrm{H}_{2} \mathrm{O}_{2}$ formed by the anodic side reaction, enabling the enzymatic biobattery to effectively operate in a membraneless configuration.

\section{Conclusion}

A membraneless rechargeable glucose biobattery combining a GOx bioanode and a PB thin-film cathode was presented. The use of PB diminishes problems associated with the formation of peroxide as a function of GOx side reactions taking place at the bioanode, as the PB is known to be highly electroactive towards reducing $\mathrm{H}_{2} \mathrm{O}_{2}$. In this regard, the role of PB is significant especially in membraneless designs where $\mathrm{H}_{2} \mathrm{O}_{2}$ can diffuse to the cathodic side of the EFCs and destabilize the performance of enzyme-based cathodes. Moreover, solid-state PB cathodes may replace cathodes that deplete dissolved $\mathrm{O}_{2}$ in the electrolyte, overcoming diffusion overpotentials and improving the overall performance. PB has also been recognized by its two redox pairs (PW/PB at low potentials and PB/BG at high potentials), allowing it to function as a rechargeable cathode material.

All these features along with the biocompatibility of the materials utilized in this category of glucose biobatteries enable its use as an energy harvester in in vivo environments where soluble electron donors (and not the electron acceptors) are easily exploitable. Specifically, this biobattery is potentially useful in an intravenous environment where the bioelectrodes are embedded into the walls of blood vessels and take advantage of the enhanced mass transfer afforded by the blood circulation. However, to apply this concept to biological samples, the bioelectrodes need to be engineered on the nano-scale to reduce the size of the device while maintaining or even increasing the reaction sites, sensitivity, and stability of the glucose oxidizing anode and PB reducing cathode. 


\section{Acknowledgement}

This work was supported by the National Science Foundation (NSF) [grant number: 1158943].

\section{References}

[1] M. Rasmussen, S. Abdellaoui, S.D. Minteer, Biosensors and Bioelectronics, 76 (2016) 91-102.

[2] M.T. Meredith, S.D. Minteer, Annual Review of Analytical Chemistry, 5 (2012) 157-179.

[3] A.A. Yazdi, L. D’Angelo, N. Omer, G. Windiasti, X. Lu, J. Xu, Biosensors and Bioelectronics, 85 (2016) 536-552.

[4] D. Pankratov, R. Sundberg, J. Sotres, I. Maximov, M. Graczyk, D.B. Suyatin, E. González-Arribas, A. Lipkin, L. Montelius, S. Shleev, Journal of Power Sources, 294 (2015) 501-506.

[5] R.D. Milton, K. Lim, D.P. Hickey, S.D. Minteer, Bioelectrochemistry, 106 (2015) 56-63.

[6] L. Zhang, L. Chen, X. Zhou, Z. Liu, Advanced Energy Materials, 5 (2015).

[7] Y. Ogawa, Y. Takai, Y. Kato, H. Kai, T. Miyake, M. Nishizawa, Biosensors and Bioelectronics, 74 (2015) 947-952.

[8] S. Aquino Neto, R.D. Milton, D.P. Hickey, A.R. De Andrade, S.D. Minteer, Journal of Power Sources, 324 (2016) 208 214.

[9] K. Monsalve, I. Mazurenko, N. Lalaoui, A. Le Goff, M. Holzinger, P. Infossi, S. Nitsche, J. Lojou, M. Giudici-Orticoni, S. Cosnier, Electrochemistry Communications, 60 (2015) 216-220.

[10] M.J. González-Guerrero, J.P. Esquivel, D. Sánchez-Molas, P. Godignon, F.X. Muñoz, F.J. Del Campo, F. Giroud, S.D. Minteer, N. Sabaté, Lab on a Chip, 13 (2013) 2972-2979.

[11] C. Fischer, A. Fraiwan, S. Choi, Biosensors and Bioelectronics, 79 (2016) 193-197.

[12] S. Calabrese Barton, J. Gallaway, P. Atanassov, Chemical reviews, 104 (2004) 4867-4886.

[13] T. Miyake, K. Haneda, N. Nagai, Y. Yatagawa, H. Onami, S. Yoshino, T. Abe, M. Nishizawa, Energy \& Environmental Science, 4 (2011) 5008-5012.

[14] X. Xie, M. Ye, C. Liu, P.-C. Hsu, C.S. Criddle, Y. Cui, Energy \& Environmental Science, 8 (2015) 546-551.

[15] P. Padigi, J. Thiebes, M. Swan, G. Goncher, D. Evans, R. Solanki, Electrochimica Acta, 166 (2015) 32-39.

[16] Y. You, X. Yu, Y. Yin, K.-W. Nam, Y.-G. Guo, Nano Research, 8 (2015) 117-128.

[17] H.-W. Lee, R.Y. Wang, M. Pasta, S.W. Lee, N. Liu, Y. Cui, Nature communications, 5 (2014).

[18] H. Lee, Y.-I. Kim, J.-K. Park, J.W. Choi, Chemical Communications, 48 (2012) 8416-8418.

[19] S. Liu, G. Pan, G. Li, X. Gao, Journal of Materials Chemistry A, 3 (2015) 959-962.

[20] R. Trócoli, F. La Mantia, ChemSusChem, 8 (2015) 481-485.

[21] Z. Jia, B. Wang, Y. Wang, Materials Chemistry and Physics, 149 (2015) 601-606.

[22] Z. Liu, G. Pulletikurthi, F. Endres, ACS applied materials \& interfaces, 8 (2016) 12158-12164.

[23] A.A. Karyakin, E.A. Puganova, I.A. Bolshakov, E.E. Karyakina, Angewandte Chemie International Edition, 46 (2007) 7678-7680.

[24] A.A. Karyakin, O.V. Gitelmacher, E.E. Karyakina, Analytical Chemistry, 67 (1995) 2419-2423.

[25] A.N. Sekretaryova, V. Beni, M. Eriksson, A.A. Karyakin, A.P. Turner, M.Y. Vagin, Analytical chemistry, 86 (2014) 9540-9547.

[26] Y. Yu, M. Xu, S. Dong, Chemical Communications, 52 (2016) 6716-6719.

[27] P.K. Addo, R.L. Arechederra, S.D. Minteer, Journal of Power Sources, 196 (2011) 3448-3451.

[28] R.D. Milton, F. Giroud, A.E. Thumser, S.D. Minteer, R.C. Slade, Physical Chemistry Chemical Physics, 15 (2013) 19371-19379.

[29] R.D. Milton, F. Giroud, A.E. Thumser, S.D. Minteer, R.C. Slade, Electrochimica Acta, 140 (2014) 59-64.

[30] S.A. Merchant, T.O. Tran, M.T. Meredith, T.C. Cline, D.T. Glatzhofer, D.W. Schmidtke, Langmuir, 25 (2009) 77367742 . 
[31] S.A. Merchant, M.T. Meredith, T.O. Tran, D.B. Brunski, M.B. Johnson, D.T. Glatzhofer, D.W. Schmidtke, The Journal of Physical Chemistry C, 114 (2010) 11627-11634.

[32] T.J. Thomas, K.E. Ponnusamy, N.M. Chang, K. Galmore, S.D. Minteer, Journal of membrane science, 213 (2003) 55 66.

[33] N.L. Akers, C.M. Moore, S.D. Minteer, Electrochimica Acta, 50 (2005) 2521-2525.

[34] A. Dawn, T. Shiraki, S. Haraguchi, H. Sato, K. Sada, S. Shinkai, Chemistry-A European Journal, 16 (2010) 3676-3689.

[35] M. Minson, M.T. Meredith, A. Shrier, F. Giroud, D. Hickey, D.T. Glatzhofer, S.D. Minteer, Journal of The Electrochemical Society, 159 (2012) G166-G170.

[36] R.D. Milton, F. Giroud, A.E. Thumser, S.D. Minteer, R.C. Slade, Chemical Communications, 50 (2014) 94-96.

[37] S.A.M. Shaegh, N.-T. Nguyen, S.M.M. Ehteshami, S.H. Chan, Energy \& Environmental Science, 5 (2012) 8225-8228.

[38] G. Selvarani, S. Prashant, A. Sahu, P. Sridhar, S. Pitchumani, A. Shukla, Journal of Power Sources, 178 (2008) 86-91.

[39] M.T. Meredith, D.-Y. Kao, D. Hickey, D.W. Schmidtke, D.T. Glatzhofer, Journal of the Electrochemical Society, 158 (2011) B166-B174.

[40] A.A. Karyakin, Electroanalysis, 13 (2001) 813-819.

[41] A. Heller, Physical Chemistry Chemical Physics, 6 (2004) 209-216.

[42] U. Schrçder, Angew. Chem. Int. Ed, 51 (2012) 2-5.

[43] F.C. Sales, R.M. Iost, M.V. Martins, M.C. Almeida, F.N. Crespilho, Lab on a Chip, 13 (2013) 468-474.

[44] J.A. Castorena-Gonzalez, C. Foote, K. MacVittie, J. Halámek, L. Halámková, L.A. Martinez-Lemus, E. Katz, Electroanalysis, 25 (2013) 1579-1584. 